\title{
BREVE PERCURSO HISTÓRICO ACERCA DA TRANSEXUALIDADE
}

BRIEF HISTORY ON TRANSSEXUALITY

BREVE HISTORIA SOBRE LA TRANSEXUALIDAD

\author{
Euza Aparecida da Silva Moreira* \\ Cristina Moreira Marcos*
}

\begin{abstract}
RESUMO
Este estudo pretendeu investigar o fenômeno da transexualidade, por meio de registros históricos sobre as manifestações da sexualidade em diferentes épocas e como estas eram explicadas de forma naturalista. Intentamos estudar como eram concebidos o sexo e o gênero nos séculos XV a XIX, e como os discursos científicos vieram, por sua vez, ordenar e especificar o que era próprio ao masculino e ao feminino. Pretendemos averiguar como o aperfeiçoamento das técnicas cirúrgicas e hormonais contribuíram para elevar a transexualidade à categoria de fenômeno social. Apresentamos os estudos Queer com o intuito de compreendermos como se entende a constituição das identidades dentro de uma determinada estrutura social. Discutimos também o posicionamento de Judith Butler em relação aos constructos sexo e gênero fundados nas categorias binárias. Por fim, demonstramos de que modo o conceito de gênero foi introduzido e abordado na psicanálise pelo psicanalista/psiquiatra Robert Stoller.
\end{abstract}

Palavras-chave: Transexualidade. Sexualidade. Teoria Queer. Robert Stoller.

\begin{abstract}
This study aimed to investigate the phenomenon of transsexuality through historical records on the manifestations of sexuality at different times, and how these were explained in a naturalistic way. We seek to study how sex and gender were conceived in the fifteenth and nineteenth centuries, and how the scientific discourses came, in turn, to order and specify what was proper to the masculine and the feminine. We intend to investigate how the improvement of surgical and hormonal techniques have contributed to elevate transsexuality to the category of social phenomenon. We present the Queer studies in order to understand how one understands the constitution of identities within a social structure. We also discuss Judith Butler's position on the sex and gender constructs based on the binary categories. Finally, we
\end{abstract}

\footnotetext{
Texto recebido em 13 de junho de 2017 e aprovado para publicação em 14 de agosto de 2018.

* Mestra em Psicologia pela Pontifícia Universidade Católica de Minas Gerais. E-mail: emoreira5@hotmail.com.

"* Doutora em Psicanálise pela Universidade de Paris 7, docente no Programa de Pós-Graduação em Psicologia da PUC Minas, psicanalista. E-mail: cristinammarcos@gmail.com.
} 
demonstrate how the concept of gender was introduced and approached in psychoanalysis through the psychoanalyst/psychiatrist Robert Stoller.

Keywords: Transsexuality. Sexuality. Queer theory. Robert Stoller.

\section{RESUMEN}

Este estudio pretendió investigar el fenómeno de la transexualidad a través de registros históricos sobre las manifestaciones de la sexualidad en diferentes épocas, y como éstas se explicaban de forma naturalista. Buscamos estudiar cómo era concebido el sexo y el género en los siglos XV a XIX y cómo los discursos científicos vinieron a su vez a ordenar y especificar lo que era propio al masculino y al femenino. Pretendemos averiguar cómo el perfeccionamiento de las técnicas quirúrgicas y hormonas contribuyó a elevar la transexualidad a la categoría de fenómeno social. Presentamos los estudios Queer con el propósito de comprender cómo se entiende la constitución de las identidades dentro de una determinada estructura social. También discutimos el posicionamiento de Judith Butler en relación a los constructos sexo y género fundados en las categorías binarias. Finalmente, demostramos de qué modo el concepto de género fue introducido y abordado en el psicoanálisis a través del psicoanalista/psiquiatra Robert Stoller.

Palabras clave: Transexualidad. Sexualidad. Teoría Queer. Robert Stoller.

\section{INTRODUÇÃO}

O fenômeno da transexualidade é um dos temas mais discutidos na atualidade. O que o caracteriza é a reivindicação que o sujeito transexual faz em querer mudar o sexo de sua conformação anatômica para o sexo oposto, ao qual ele acredita pertencer. A questão que ele apresenta em relação à sua identidade sexual gira em torno da disjunção entre o seu sexo e o gênero que almeja alcançar. Para que tal feito se realize, o sujeito transexual conta com o aperfeiçoamento das técnicas cirúrgicas e hormonais, que lhe garantam redesignar o seu sexo por meio da cirurgia.

Esse ambicionar passar para o sexo oposto seria um desejo somente do sujeito transexual na Contemporaneidade? Registros históricos apontam que não. Já em outras épocas, sujeitos desejavam passar para o sexo oposto, seja pelas vestimentas ou mesmo por outros modos de expressão da sexualidade. 


\section{A MITOLOGIA E A TRANSEXUALIDADE}

O desejo de mudar de sexo existia muito antes da criação do termo transexualismo. Para tanto, seguiremos por um breve percurso através das mitologias grega e latina. Usaremos o mito, pois, além de ser nossa primeira forma de narrativa, teve como função explicar a realidade humana.

$\mathrm{Na}$ mitologia, três personagens dão conta desse fenômeno: Cibele, Ártis e Hermafrodito. Cibele, grande deusa, era o nome latino da deusa chamada pelos gregos de Rea ou Ops. Era esposa de Cronos e mãe de Zeus. Trata-se de uma divindade anatoliana, ${ }^{1}$ que foi importada da Frígia ${ }^{2}$ e levada ao mundo grecoromano. Seu filho e amante, Ártis, guardião de seu templo, foi proibido de se casar. Enlouquecido, ele se castrou e se matou. Os adeptos do culto de Cibele adquiriram o hábito de se mutilar em meio à orgia e à embriaguez.

Hermafrodito, filho de Hermes e de Afrodite, rapaz dotado de rara beleza, nega-se ao amor de uma ninfa, que o enlaça e se une a ele para sempre. Os deuses dos dois corpos fizeram uma só pessoa com dupla natureza.

$\mathrm{Na}$ história de Dafne, primeiro amor de Apolo, está inscrito o horror à ideia de amar (ou da relação sexual). Temendo o casamento como se fosse um crime, ela suplicou ao pai Peneu, o rio-deus, que não exigisse que ela se casasse. Como castigo, foi transformada num loureiro, com cujas folhas se faz uma coroa, a coroa de louros.

No tratado dos ares, das águas e dos lugares, encontramos a famosa descrição da doença dos citas, povo da Rússia meridional, feita por Heródoto. ${ }^{3}$ Quando fracassam em suas relações com as mulheres, na primeira vez, eles não se inquietam, conservando a calma. Ao cabo de duas, três ou várias tentativas que não dão resultado, e acreditando terem cometido algum pecado contra a divindade à qual atribuíram a causa disso, eles vestem roupas de mulheres, confessam sua impotência. Depois, assumem a voz de mulheres e executam, a seu lado, o mesmo trabalho que elas.

Continuando esse percurso, citaremos casos levantados na literatura moderna da França, em fabliaux, ${ }^{4}$ que são contos populares medievais, e em histórias da literatura médica, casos de mudança de sexo.

1 Anatólia é o nome dado à Ásia Menor.

2 Frígia é região que ocupava parte do platô anatoliano.

3 Heródoto: sábio grego (-424/-425), considerado o pai da história, narrador de grande qualidade.

4 Fabliaux: pequeno texto em verso de oito sílabas, que tem como objetivo divertir ou edificar, que era próprio da literatura dos séculos XIII e XIV. 


\section{HISTÓRIA DA TRANSEXUALIDADE: ERA UMA VEZ... UM GÊNERO E UM SEXO...}

Para tratarmos do percurso histórico da transexualidade, vamos nos referir primeiramente a Millot et al. (1988), que aborda sobre os primeiros registros acerca da transexualidade que haviam sido publicados em um artigo de uma revista do interior da França, descoberto em um arquivo religioso mais ou menos no século XV, no qual se relata a história de uma mulher que chegou "como homem" a um povoado de Champanhe, região da França.

Fazendo se passar por homem, essa mulher se casou. E, ao que consta, ela vivia feliz e fazia feliz a mulher com quem vivia, principalmente por suas práticas sexuais. Ficando viúvo, casou-se pela segunda vez. Tudo o que se relacionava ao sexo dessa personagem somente veio ao conhecimento de todos quando ela adoeceu. "Esse homem" portava um tipo de pênis artificial de fabricação própria, com o qual praticava o coito com suas esposas (Millot et al., 1988, p. 18).

Outro exemplo de transexualidade, célebre na França, é o do Chevalier D'Eon/Madame Beaumont, excelente espadachim, que pertenceu ao serviço secreto francês e era alto funcionário do rei Luís XV55 (Bento, 2008, p. 13).

Por 49 anos, Charles D'Eon de Beaumont foi uma mulher que, algumas vezes, vestia-se de homem. Pela maneira como vivia, parecia tratar-se de um homem, o que acabava provocando rumores públicos e dúvidas em relação a seu sexo.

Para o Chevalier D’Eon/Madame Beaumont exercer suas funções de espiã(o) ou para ser reconhecido como mulher socialmente, o trânsito entre o masculino e o feminino era consumado por ele de forma natural e não comprometia sua posição na corte francesa e nem perante o rei Luís XV. O modo de proceder de Charles D'Eon revelava a tolerância do rei e da sociedade francesa em relação a seu comportamento e indicava uma aceitação no que diz respeito à sua indefinição sexual, dado que não se tentava apregoar um caráter moral e determinista de naturalização das condutas. "Evidenciava-se, assim, que a relação entre corpo e gênero, que sugeria uma leitura e determinação do que é masculino/feminino, não estava, necessariamente, condicionada à genitália" (Bento, 2008, p. 14).

Entre os casos de mudança de gênero, a pesquisa de Laqueur resgata a história de Germain Garnier, que viveu como uma menina. Esse fato foi relatado pelo

5 Luís XV: rei da França (1715-1774). Apesar de ser um monarca pouco firme em suas decisões, a França viveu um momento de grande prosperidade e conheceu uma época brilhante em sua civilização e cultura (Robert, 2012). 
cirurgião-chefe de Carlos IX, ${ }^{6}$ Ambroise Paré, ${ }^{7}$ e este não especifica, em seu relato, se o caso era de ambiguidade sexual ou mesmo de transexualidade.

A narrativa de Paré sobre Marie-que-virou-Germain se encontra em uma coleção de histórias e observações clínicas, nas quais consta de que movimentos bruscos foram a causa da mudança de gênero (Laqueur, 2001, pp. 162-163).

Trata-se da história de Germain Garnier, batizado como Marie, que servia o rei Carlos IX, quando o famoso cirurgião o(a) conheceu. Ele era um rapaz de corpo bem-feito, com uma barba vermelha cerrada, e, até os 15 anos de idade, havia vivido como mulher, sem demonstrar qualquer sinal de masculinidade.

Conta-se que, no período de sua puberdade, a menina Marie havia saltado por cima de uma vala quando corria atrás dos porcos, num campo de trigo. Naquele momento, a genitália se desenvolveu nela, rompendo os ligamentos que até então a prendiam. Marie foi até a casa e procurou pela mãe, que consultou médicos e cirurgióes, os quais lhe garantiram que sua "filha" agora era seu "filho". Um bispo do lugar declarou, em assembleia, que realmente havia ocorrido uma transformação. Dessa forma, Marie passou a se chamar Germain e ganhou roupas masculinas (Laqueur, 2001, p. 163).

Ambroise Paré oferece uma explicação inteiramente naturalista para esse caso, que foi recontado por Michel de Montaigne. ${ }^{8}$ Essa explicação se pautou em um argumento de acordo com o qual movimentos violentos teriam possibilitado a soltura dos ligamentos e o desenvolvimento de um órgão sexual masculino. Para o médico Paré, essa mudança de gênero no caso Germain/Marie não apresenta nada de extraordinário (Laqueur, 2001, pp. 163-164).

Laqueur (2001, p. 164) afirma que os registros de Paré e de tantos outros autores de longa tradição consideram que a mulher pode tornar-se homem a qualquer momento ou que o homem pode perder seu membro e tornar-se mulher. Nesse mundo imaginativo, que argumenta sobre o tornar-se homem ou mulher, descrito em sua pesquisa, o autor afirma que "não há um sexo real que, em princípio, baseie e distinga de forma reducionista os dois gêneros. O gênero é parte da ordem de coisas, e o sexo, se não inteiramente convencional, tampouco é solidamente corpóreo" (Laqueur, 2001, p. 165).

Quando se pensa em termos atuais sobre esse texto escrito na Renascença, questiona-se o que acontece com o sexo quando o desempenho dos gêneros se

6 Carlos IX: rei da França de 1560-1574, era filho de Catarina de Médici e sucedeu a seu irmão Francisco II. Cedendo à pressão católica, ordenou o massacre de São Bartolomeu.

7 Ambroise Paré: cirurgião francês (séc. XVI). Depois de ter sido barbeiro-cirurgião, tornou-se médico de Henrique II e dos filhos desse rei. Autor de diversos tratados científicos, ele é considerado pai da cirurgia moderna.

8 Michel de Montaigne: escritor francês, viveu de 1533 a 1592. Autor de Essais (Ensaios), ele se tornou conhecido sobretudo por essa obra, conjunto de 107 capítulos, composto por três livros. 
torna indistinto, não operacionaliza. Nessa época, aquilo a que hoje chamamos de sexo e gênero é que está ligado a um círculo de significados, que torna impossível pensar em um suposto substrato. Segundo Laqueur (2001, pp. 164165), o suposto real e imaginário, o representativo e o verdadeiro, o falo e o pênis, estão irremediavelmente misturados.

No Período Renascentista, os médicos consideravam que havia um sexo único. Porém existia, de alguma forma, a manifestação de pelo menos dois sexos sociais. Esses dois sexos tinham direitos e obrigações radicalmente distintos, e relacionavam-se aos graus, mais altos ou mais baixos, da escala corpórea do ser.

Segundo pesquisa de Bento (2008, p. 20), até meados do século XVII, o que imperava entre os anatomistas era a proposição do isomorfismo: a existência de um corpo e pelo menos dois gêneros. Pelo isomorfismo, o útero era o escroto feminino; os ovários, os testículos; a vulva, um prepúcio; e a vagina, um pênis invertido.

A mulher, por ser fisiologicamente um homem invertido, carregava dentro de si tudo o que o homem trazia exposto. Nada havia de extraordinário no fato de uma menina, por alguma contingência, tornar-se um menino, era o que pensavam os anatomistas.

De acordo com o isomorfismo, a energia necessária para gerar a vida estava concentrada no homem, e a mulher, por ter um calor corporal menos intenso ou ser considerada como um homem imperfeito, teria, em seu corpo, a semente produzida pelo calor vital do homem. "No modelo que se apresenta no isomorfismo, o corpo é representado por continuidade; a diferença é representada em termos de graus (mais quente/menos quente) da escala corpórea do ser" (Bento, 2008, p. 22).

Para Laqueur, nenhum tipo de sexo (social ou biológico) podia ser cogitado como fundamental ou básico, embora as divisões de gênero (as categorias do sexo social) fossem certamente consideradas naturais. Laqueur (2001) declara:

O sexo biológico, que nós geralmente usamos como base do gênero, era tão existente no domínio da cultura e do significado quanto o gênero. O pênis era, portanto, um símbolo de status e não um sinal de alguma outra essência ontológica profundamente arraigada: o sexo real. Podia ser interpretado como um simples certificado, como o diploma de um médico ou advogado, cujo portador tinha certos direitos e privilégios (p. 170).

No estudo apresentado por Laqueur, o sexo era determinado de forma que pudesse adequar-se à pessoa em categorias claras e não ambíguas de gênero, indicando, dessa maneira, que ele era estabelecido atrelado à sua natureza cultural e não era considerado um problema. 
Desse modo, as determinações se delineavam da seguinte maneira: as pessoas com pênis externo eram consideradas como meninos e tinham todos os privilégios e obrigações dessa condição; e as que tinham um pênis interno pertenciam à categoria inferior de meninas.

A genitália, porém, era vista como um fundamento inseguro. As modificações no corpo podiam fazer com que ele passasse facilmente de uma categoria jurídica (feminina) para outra (masculina). Essas categorias se sustentavam nas distinções de gênero (ativo/passivo, quente/frio, com forma/sem forma), sendo o pênis externo ou interno apenas um sinal diagnóstico. Para os magistrados da época, a realidade corpórea, ou sexo, era o que menos preocupava, o que mais importava era a manutenção de categorias sociais.

Como o sexo era, ainda, uma categoria sociológica, não ontológica, durante grande parte do século XVII, ser homem ou mulher era manter uma posição social, assumir um papel cultural e não se vincular organicamente a um sexo ou outro (Laqueur, 2001, p. 177).

Por volta dos séculos XVIII e XIX, as diferenças biológicas entre homens e mulheres se tornaram consistentes por meio dos discursos científicos, que foram antecedidos pela rediscussão do que se apregoava como estatuto social da mulher e do homem. Por volta da segunda metade do século XVIII, ganham relevância as diferenças anatômicas e fisiológicas visíveis, que até então não eram consideradas para distinguir, biologicamente, homens e mulheres (Bento, 2008, p. 20).

Até então, os órgãos que tinham nomes associados (ovários e testículos) passaram a ser diferenciados em termos linguísticos, e os que não eram nomeados especificamente, como a vagina, passaram a ser. As estruturas que eram consideradas comuns ao homem e à mulher (o esqueleto e o sistema nervoso) foram diferenciadas de maneira a contemplar o que correspondia culturalmente ao homem e à mulher.

O levantamento bibliográfico realizado por Laqueur (2001) demonstra que se, no século XVII, alguns textos lançavam mão do argumento biológico para explicar a ordem moral, ao longo dos séculos XVIII e XIX, esse quadro mudou, e as produções científicas apontavam a importância das diferenças sexuais na definição dos comportamentos (Laqueur, 2001, p. 192). Nos anos de 18601870, os discursos médicos se pluralizavam na tentativa de comprovar que os comportamentos sexuais tinham sua origem na biologia (Bento, 2008, p. 21).

No século XVIII, inventou-se o sexo que nós conhecemos e corporificou-se não somente uma rejeição ao modelo do isomorfismo, mas também uma certa aversão em relação à ideia de que as diferenças sutis entre os órgãos, fluidos e 
processos fisiológicos refletiam uma ordem transcendental de perfeição.

Em meados do século XIX, nova proposição de interpretação dos corpos ganhou força: o dimorfismo. ${ }^{9}$ No dimorfismo, essa interpretação consistia no fato de que existiram dois corpos diferentes, radicalmente opostos, e no fato de que as justificativas para as condutas dos gêneros estariam nesses corpos.

Dessa forma, pela oposição binária, os trânsitos entre os gêneros foram interrompidos, pois todo sujeito tem um sexo, e a ciência deveria determinar o sexo verdadeiro mediante um exame minucioso. Eram os corpos que iriam comprovar as diferenças entre o masculino e o feminino, e os discursos dessa diferença sexual dariam o suporte, com base num discurso científico, à determinação das condutas.

Todos os quesitos de distinção entre homens e mulheres eram usados nessa concepção, para considerar que eles apresentavam diferenças irrelativizáveis. Da espessura da pele ao tamanho do crânio, da estrutura psíquica aos complexos, tudo era diferença.

A refinada engenharia da diferença sexual esquadrinhou os corpos visando a provar que não existe fator comum entre o feminino e o masculino. $\mathrm{O}$ único fator comum poderia concretizar-se somente no ato sexual. Pelo dimorfismo, a organização social deveria ser orientada pela natureza (Bento, 2008, p. 23).

Podemos nos deter, porém, no fato de que o novo conhecimento sobre o sexo não agregou, de maneira alguma, nada de inédito às afirmaçôes sobre a diferença sexual proclamadas em seu nome. Nada de novo ou nenhuma descoberta fomentou o modelo de dois sexos, do mesmo modo que, na Renascença, não justificaram o modelo de sexo único.

A natureza da diferença sexual não é suscetível a exame empírico, mas se impregna na linguagem da ciência, quando aplicada em alguma construção cultural que diz respeito a essa diferença, endossando a linguagem de gênero (Laqueur, 2001, p. 193).

Apesar de o aporte científico trazer como base a condição epistemológica da natureza, para explicar as distinções sexuais e apesar do repertório de fatos sobre o sexo, a diferença sexual, pós-revolução científica, não ficou mais estável do que era. Os dois sexos, entre si, incomparáveis, ainda são o resultado da cultura como era no modelo de sexo único. Modelos esses que imprimem, pela ciência, que a relação entre o homem e a mulher não é de igualdade ou desigualdade, mas de diferença, e que essa diferença é passível de interpretação.

9 Dimorfismo: propriedade de certos corpos, de certas espécies animais ou vegetais que se apresentam sob duas formas distintas (Robert, 2012). 


\section{A TRANSEXUALIDADE NO SÉCULO XX}

O termo "transexual" foi cunhado pelo doutor D. O. Caudwell, em 1949, em um artigo publicado na revista de educação sexual de Gernsback, Sexology (hoje desaparecida). Nessa época, essa revista era subsidiada por esse mesmo editor, que publicava duas outras revistas: Science Fiction e Sports Illustrated. Ramsey esclarece: "Sexualmente explícita, (a revista) foi banida pelo inspetor postal dos EUA, tendo que ser vendida às escondidas nas bancas de jornais. Tal era o ambiente sexológico no qual a transexualidade fez a sua primeira aparição" (Ramsey, 1998, p. 17).

O termo transexualismo foi criado, no ano de 1953, por Harry Benjamin, médico clínico que se tornou conhecido como "pai da transexualidade". Benjamin, após a Primeira Guerra Mundial, estabeleceu-se em Nova Iorque, pertencendo à primeira geração de endocrinologistas dos Estados Unidos. "Quando fez 60 anos, ao invés de se aposentar, lançou-se numa segunda carreira, especializando-se em transexualidade" (Ramsey, 1998, p. 17). O termo, portanto, foi introduzido pelo psiquiatra norte-americano Benjamin, para designar um distúrbio puramente psíquico da identidade sexual, caracterizado pela convicção inabalável que tem um sujeito de pertencer ao sexo oposto.

Para os dicionaristas Roudinesco e Plon (1998), somente o transexualismo (como foi dito, distúrbio puramente psíquico da identidade sexual) leva o sujeito a transformar/mudar seu órgão sexual normal num órgão do sexo oposto, valendo-se, para isso, de uma intervenção cirúrgica.

Complementando as suas observações a respeito do termo transexualismo, Roudinesco e Plon têm oportunidade de usar o termo transexual e de conceituálo, ainda que de maneira indireta:

Assim, o transexual masculino tem a convicção de ser uma mulher, embora, anatomicamente seja um homem normal. Do mesmo modo, a mulher transexual está convencida de ser homem, embora seja mulher em termos anatômicos (Roudinesco \& Plon, 1998, p. 765).

O Dicionário de psicanálise não apresenta, entre seus verbetes, a palavra transexual nem transexualidade.

A conceituação, apresentada por esse dicionário, do termo transexualismo evidencia a convicção do sujeito em pertencer ao sexo oposto ou mesmo o sentimento de inadequação com o próprio sexo. Nesse sentido, essa inadequação no que diz respeito ao corpo sempre foi própria do sujeito. Freud (1893- 
1895/1996, p. 283) ${ }^{10}$, quando escuta as histéricas, observa que é esse desacordo em relação ao seu sexo que elas expressavam.

Dos famosos casos de histeria apresentados na obra freudiana, destaca-se o caso da neurose de Dora, que traz a questão histeria: o que é ser uma mulher? Lacan destaca, no percurso do complexo de Édipo freudiano, as analogias e simetrias que marcam menino e menina, ao atravessarem o complexo. Ressalta, ainda, o que é essencial nesse complexo: a dissimetria num e noutro sexo. Essa simetria se localiza em nível do simbólico, que depende do significante:

Não há, propriamente, diremos nós, simbolização do sexo da mulher como tal. Em todo o caso, a simbolização não é a mesma, não tem a mesma fonte, não tem o mesmo modo de acesso que a simbolização do sexo do homem. E isso, porque o imaginário fornece apenas ausência, ali onde alhures há um símbolo muito prevalente (Lacan, 1955-1956/1988, p. 201).

Sobre o conceito de "gênero", encontramos as seguintes definições: "O termo gênero provém do latim genus, generis, com o significado de 'classe', 'espécie'. Essa palavra serve para designar 'qualquer categoria, classe, grupo ou família que apresente os mesmos sinais comuns'” (Roudinesco \& Plon, 1998, p. 291).

Nesse dicionário, esclarecem os autores que o termo gênero foi empregado como conceito pela primeira vez por Stoller, em 1964. Serviu inicialmente para distinguir o sexo (no sentido anatômico) da identidade (no sentido social ou psíquico). Nessa acepção, portanto, o gênero designa o sentimento (social ou psíquico) da identidade sexual, enquanto o sexo define a organização anatômica da diferença entre o macho e a fêmea.

A socióloga brasileira Heleieth Saffioti, em sua obra Gênero, patriarcado, violência (Saffioti, 2004), faz uso da categoria gênero, ampliando o entendimento de que gênero também diz respeito a uma categoria histórica, cuja investigação demanda intenso investimento intelectual e pode ser concebido em várias instâncias:

Gênero: como aparelho semiótico (Lauretis, 1987); como símbolos culturais evocadores de representações, conceitos normativos como grade de interpretação de significados, organizaçôes e instituiçôes sociais, identidade subjetiva (Scott, 1988); como divisōes e atribuiçôes assimétricas de característicos e potencialidades (Flax, 1987); como, numa certa instância, uma gramática sexual, regulando não apenas relaçōes homem-mulher, mas também relações homem-homem e relações mulher-mulher (Saffioti, 2004, p. 45).

10 A primeira data indica o ano de publicação original da obra, e a segunda, a edição consultada pelo autor, a qual somente será pontuada na primeira citação da obra no texto. Nas seguintes, será registrada apenas a data de publicação original. 
Até 1966, o conceito de gênero havia sido aplicado no hermafroditismo por Money (1955) em expressões como "papel de gênero" ou "identidade de gênero", ou identidade/função de gênero.

$\mathrm{O}$ conceito de identidade de gênero ficou intrinsecamente ligado à transexualidade, quando, no ano de 1966, o Hospital Johns Hopkins anunciou a formação da sua Clínica de Identidade de Gênero e a sua primeira cirurgia de mudança de sexo num caso de transexualidade. Esse não foi, contudo, o primeiro caso desse tipo nos Estados Unidos. O cirurgião urologista, Elmer Belt, já havia conduzido uma série pouco duradoura de operações transexuais em Los Angeles.

A criação da Clínica de Identidade de Gênero Johns Hopkins estimulou a formação de clínicas semelhantes em outros espaços. Em 1980, quando a Associação Psiquiátrica Americana (APA) publicou a terceira edição do seu Diagnostic and statistic manual ou mental disorders III - DSM-III (Manual de diagnósticos e estatísticas de distúrbios mentais III), este incluía uma nova seção sobre distúrbios de identidade de gênero, na qual estavam agrupadas três entidades: "transexualidade", "distúrbios de identidade de gênero da infância" e "distúrbio de identidade de gênero atípica" (Ramsey, 1998, p. 18).

Por essa classificação, e embora a transexualidade tenha alcançado o reconhecimento nosológico no DSM-III, a cirurgia de mudança de sexo era objeto de disputa profissional, advinda dos problemas relacionados à "moralidade médica”, obtendo mais valor do que as avaliaçôes dos dados levantados. Essa moralidade se vinculava ao conceito mente/corpo e questionava intervir e provocar uma mudança no corpo por meio da cirurgia e pelo uso de hormônios. Essa intervenção visava a provocar mudança no corpo, de modo que este estivesse de acordo com a mente.

$\mathrm{Na}$ publicação de Ramsey, encontram-se as palavras de Money. "Na medida em que não há forma conhecida de intervenção por via da qual modificar a mentalidade transexual, ou mais especificamente, mudar a identidade transexual de gênero, a alternativa é não fazer nada" (Ramsey, 1988, p. 18).

Também nos anos 1980, destacou-se o trabalho da filósofa norte-americana Judith Butler, que fundamentou sua teoria dialogando com a psicanálise e com as obras de Hegel, Foucault, Derrida, entre outros (Salih, 2015, p. 15).

Segundo a autora, até o fim dos anos 1980, Butler esteve trabalhando a respeito de Hegel e do impacto de sua obra, Fenomenologia do espírito, por duas gerações de filósofos franceses do século XX. As contribuições de Michel Foucault no trabalho da filósofa giram em torno das análises históricas das construções do sexo e da sexualidade, em diferentes sociedades e contextos. Para falar sobre 
o sujeito, Butler complementa seu estudo pelas teorias linguísticas do filósofo francês Jacques Derrida. O objetivo do livro, produto desse trabalho, Subjects of desire, era compreender como o sujeito se constituía em estruturas de poder marcadas pela definição do que é sexo e o que é gênero.

Nessa época, o termo gênero referenciava não somente o papel social e cultural do sexo biológico, como também era usado para explicá-lo. A diferença entre sexo e gênero atendia à proposição de que, por mais que o sexo pareça intratável em termos biológicos, o gênero é culturalmente construído. Como consequência dessa proposição, "O gênero não é nem o resultado causal do sexo, nem tampouco tão aparentemente fixo quanto o sexo" (Butler, 2016, p. 26).

Butler (2016, p. 26) levanta a hipótese de que o sistema binário instituído explica o gênero relacionado ao sexo, ou seja, é o sexo que limita o gênero. A ideia de gênero definida pelo sistema determinava a verdade da sexualidade.

Diante do determinismo que impõe tal concepção de gênero, Butler (2016, pp. 26-27) questiona em que termos dar-se-ia tal determinismo. Como considerar um "dado" sexo ou um "dado" gênero sem, em primeiro lugar, averiguar como o sexo e o gênero são determinados e qual sua natureza?

Com base nesse questionamento que a autora faz em relação ao caráter do sexo, ela levanta a hipótese de que, assim como o constructo gênero, o constructo sexo seja também culturalmente construído, não havendo diferença. Dessa maneira, não há sentido em determinar o gênero como interpretação cultural do sexo. $\mathrm{Na}$ palavra de Butler (2016):

Resulta daí que o gênero não está para a cultura como o sexo para a natureza; ele também é o meio discursivo/cultural pelo qual "a natureza sexuada" ou "um sexo natural" é produzido e estabelecido como "pré-discursivo", anterior à cultura, uma superfície politicamente neutra sobre a qual age a cultura (p. 27).

De acordo com a filósofa, sendo o sexo, assim como o gênero, estabelecido como pré-discursivo acaba por fortalecer a estrutura binária já instituída, que determina que o conceito de gênero está diretamente ligado à anatomia. Sendo o gênero e o sexo apresentados dessa forma, como dependente dessa determinação cultural, acabaria por inviabilizar uma análise mais aprofundada das possibilidades de configuração do gênero. 


\section{A TRANSEXUALIDADE POR ROBERT STOLLER}

Na psicanálise, o conceito de gênero é introduzido pelo psiquiatra e psicanalista americano Robert J. Stoller, autor de um trabalho sobre a identidade sexual (Millot et al., 1988, p. 19). Em seu livro A experiência transexual (Stoller, 1982, p. 1), o autor se aprofunda em questôes ligadas à masculinidade e à feminilidade, por meio do tratamento por psicanálise, ou psicoterapia psicanalítica orientada. Essas questóes, ele as relaciona com a apresentação de deformidades em órgãos sexuais (pacientes intersexuais) ou naqueles pacientes que, na ausência dessas deformidades, têm um desvio em suas identidades de gênero.

Stoller (1982) considera que a transexualidade tem cunho sexual e se apresenta como um desvio de identidade. Ele evidencia, entre outras hipóteses que levanta em seu estudo, as influências familiares, como possível etiologia da transexualidade. O tema da sua pesquisa é definido pelo autor.

Transexualismo é uma desordem pouco comum, na qual uma pessoa anatomicamente normal sente-se como membro do sexo oposto e, consequentemente, deseja trocar seu sexo, embora suficientemente consciente de seu verdadeiro sexo biológico. A condição é rara, embora não se saiba o quanto, em parte por não haver unanimidade sobre o que deva ser chamado transexual (Stoller, 1982, pp. 2-3).

Julgando como importante essas influências familiares na transexualidade masculina, Stoller (1982, p. 39) chama atenção especificamente sobre a relação simbiótica entre mãe-filho, já traçada nos primeiros anos de vida da criança, nos quais o menino começa a apresentar sua extrema feminilidade.

Outro aspecto da pesquisa do psiquiatra/psicanalista destaca que, de maneira geral, diferentemente de seu filho, na infância, a mãe do transexual era movida pelo desejo de ser um menino. Por isso ela desenvolve características masculinas marcantes que se estendem até a puberdade. Aliada a esse traço de bissexualidade, outra particularidade apresentada nessa mãe é que ela demonstra ser cronicamente deprimida, em razão da difícil relação que anteriormente havia estabelecido com sua própria mãe.

Nesse sentido, o que se apresenta, nessa relação do transexual com a sua mãe, é que ela mantém uma profusão de sentimentos extravagantes e profundos pelo filho, por anos. Nenhuma manifestação de irritação, discordância ou desejo de realização por parte dela será apresentada, fortalecendo, assim, a unidade entre os dois, sem que nada possa rompê-la. Conforme Stoller (1982, p. 45), para todas as mães, o bebê equivale a um pênis, especialmente se ele for do sexo masculino. 
Essa simbiose máxima é mantida não somente pelo fato de a criança ser muito adorada pela mãe durante anos, mas também pelo fato de seu pai dificilmente se manter em casa e, por fim, acabar estimulando essa união entre mãe e filho. Esse pai desampara esse menino dos efeitos de uma feminilização da mãe e não se apresenta como um modelo para que se estabeleça uma identificação masculina para o menino. Por essa feminilidade já se encontrar totalmente arraigada na personalidade do menino, por volta dos três anos de idade, o autor afirma que a natureza da experiência edípica será atípica, no caso do transexualismo.

O que Stoller (1982, p. 54) observa, nesse caso, é que a excessiva proximidade entre mãe e filho contribui para afastar ou extinguir uma identificação com o pai, isso porque não existe um pai presente ou uma representação mais acentuada do que seria a masculinidade. $\mathrm{O}$ menino não tem rival em relação à sua mãe; ele a possui talvez mais completamente do que outra criança, e eles são praticamente um só.

Com base na dinâmica dessa relação mãe-filho, a transexualidade masculina será definida por Stoller (1982, p. 55) fundamentalmente como uma fixação na relação simbiótica primitiva com a mãe. Essa relação simbiótica, entretanto, não é psicotizante, considerando que o desenvolvimento das funções do ego em geral e a capacidade de integração social dessas pessoas permanecem intactos.

De acordo com o autor, em outras desordens da sexualidade, o conflito edipiano exerce uma decisiva influência etiológica, o que se esperava, também, que fosse extremamente relevante para os transexuais. No caso da transexualidade masculina, frisa o autor (Stoller, 1982, p. 94), essa influência chega a ser significativa, sem conseguir, porém, alterar ou distorcer a feminilidade já existente no menino. Desse modo, o transexual, para Stoller, situa-se fora da dinâmica edipiana:

A situação edipiana no transexualismo masculino é notável pelo fato de que evidências no conflito edipiano - sentimentos incestuosos, ansiedade de castração e identificação com o pai do mesmo ego - não são vistas. É essa ausência de significante conflito edipiano, acreditamos, que permite que a identidade feminina da criança se desenvolva, daí em diante, e de forma inalterável. Atribuímos a ausência de ansiedade edipiana a anormalidades na situação da família, especialmente a ausência física e a falta de laços emocionais envolventes com o pai, e a contínua simbiose com a mãe (Stoller, 1982, p. 94).

No menino transexual, essa feminilidade tem andamento inalterado além do período edipiano e não se altera na fase adulta. O autor acredita que uma intervenção terapêutica, que ele nomeia como complexo de Édipo "terapeuticamente induzido", no período edipiano, possa produzir fantasias edipianas capazes de mudar a orientação genérica para direção da masculinidade. Essa intervenção 
do terapeuta visava a alterar as dinâmicas familiares, introduzindo certos temas edipianos que não se encontravam presentes.

Stoller (1982, p. 149) destaca, em sua obra, uma discussão entre a transexualidade e o transvestismo e os aspectos que os distingue. Para ele, o travestismo tem ligação com algo de ordem fetichística, já que o uso de roupas femininas produz excitações sexuais. Diferentemente do travesti, o transexual nunca mostrou esse tipo de excitação sexual induzida por vestimentas.

Quanto à escolha de seu objeto de amor, os transexuais são incapazes de manter relações sexuais com o sexo oposto, e invariavelmente preferem homens masculinos, homossexuais, mas que estes não demonstrem interesse pelo seu órgão sexual. Essa preferência se detém no fato de que os transexuais não têm nenhum interesse que seu pênis seja representativo de masculinidade ou mesmo usado para expressar erotismo. Alguns transexuais raramente têm orgasmos e, quando têm, fantasiam que a sensação erótica que têm está sendo sentida na vagina.

Stoller (1982, p. 172) revela, em sua pesquisa, que a diferença entre o travestismo e o transexualismo é que o transexual não se interessa pelo ato sexual e pelo órgão do macho. Já para o travesti, o ato de se vestir com roupas femininas tem o significado de ato sexual e se localiza nos genitais o prazer mais apreciado por ele, que não cogita ser uma mulher presa no corpo de um homem.

Mesmo com roupas femininas, o travesti não deseja ser uma mulher e sim uma mulher com pênis. Esse fato indica não somente a consciência de seus genitais masculinos, mesmo por baixo das roupas, bem como de sua excitação sexual. Ao contrário do transexual, julga-se homem e deseja seguir assim. Diferentemente do que acontece com o travesti, o transexual não deseja ser homem e faria qualquer coisa para deixar de sê-lo.

Para Stoller (1982), a transexualidade feminina talvez não apresente a mesma condição que a transexualidade masculina:

Embora ambos sejam o extremo da inversão de masculinidade e feminilidade, me parecem, por outro lado, diferentes clínicas, dinâmica e etiologicamente. Se fossem idênticos, isso não deveria ocorrer. Dessa forma, novamente, podemos fazer uma experiência e ver se o contraste servirá para controlar as variáveis (p. 223).

O que é a transexualidade feminina? Para Stoller, mesmo quando reconhecidamente pelos pais, a criança nasce do sexo feminino, eles não a tratam de maneira que isso possa levar crédito. Logo cedo (por volta dos 3 ou 4 anos), ela começa a apresentar comportamentos e interesses masculinos. 
A identidade sexual da menina progride em direção ao masculino. Aos 7 ou 8 anos, além de declarar à família seu desejo de transformação em homem, ela inventa para si um nome masculino e mantém postura e interesses que os meninos preferem. Quanto mais o tempo passa, mais aumenta o desejo de ser tratada e reconhecida como homem. A transexual, por volta dos 20 anos, circulará pela sociedade como tal.

As influências familiares como causa da transexualidade feminina ainda são pouco exploradas ou quase inexistentes na literatura, conforme Stoller. Portanto ele elenca algumas ideias preliminares e fatores presentes na relação estabelecida entre a transexual e sua família.

Entre os fatores que influenciam a transexualidade feminina, Stoller (1982, p. 227) exemplifica: uma criança que não correspondeu ao desejo dos pais, ao nascer ou mais tarde; uma mãe feminina que, ao nascimento dessa filha e, às vezes, mais tarde, na infância, é afastada da criança por uma doença emocional patente, severa, como a depressão; um pai masculino que, apesar disso, não está presente psicologicamente e não suporta quando a mulher está em depressão e não encoraja a feminilidade de sua filha. Dados esses fatores, a menina é levada a preencher a lacuna que seu pai deixou e a desempenhar o papel do marido que auxilia essa mãe.

Ao enveredarmos pelo percurso histórico da transexualidade, desde as épocas mais antigas até os dias atuais, deparamo-nos com a inadequação em que o sujeito transexual apresenta em relação a seu corpo. $\mathrm{O}$ sujeito transexual reivindica o direito de escolher seu sexo, acreditando ser esse diferente do que lhe foi concedido pela natureza. Diante da oferta indiscriminada da cirurgia de mudança de sexo como solucionadora da questão que permeia a transexualidade, faz-se necessário escutar o que abriga a demanda do pedido de troca de sexo, no sentido de compreendermos o sintoma transexual. 


\section{REFERÊNCIAS}

Bento, B. A. M. (2008). O que é transexualidade. São Paulo: Brasiliense.

Butler, J. P. (2016). Problemas de gênero: feminismo e subversão da identidade. Rio de Janeiro: Civilização Brasileira.

Freud, S. (1893-1895). Estudos sobre a histeria, IV: a psicoterapia da histeria. (Breuer, \& Freud). In J. Salomão (Trad.), Edição standard brasileira das obras psicológicas completas de Sigmund Freud. (Vol. 2, pp. 309-363). Rio de Janeiro: Imago, 1996. (Publicado originalmente em 1893-1895).

Lacan, J. (1955-1956). A questão histérica (II): “O que é uma mulher?”. In J. Lacan. O seminário 3: as psicoses. Rio de Janeiro: Jorge Zahar, 1988. (Publicado originalmente em 1955-1956).

Laqueur, T. W. (2001). Inventando o sexo: corpo e gênero dos gregos a Freud. Rio de Janeiro: Relume Dumará.

Millot, C. (1992). Extrasexo: ensaio sobre o transexualismo. São Paulo: Escuta.

Millot, C. et al. (1988). Transexualismo; identidade feminina: transcrição 1. (2a ed.). Salvador: Fator.

Money, J. (1955). Hermaphroditism, gender and precocity in hyperadrenocorticism: psychologic findings. Bulletin of the Johns Hopkins Hospital, 96, 253-264.

Ramsey, G. (1998). Transexuais: perguntas e respostas. São Paulo: Summus.

Robert, P. (2012). Le petit Robert: dictionnaire alphabetique et analogique de la langue française. Paris: Le Robert.

Roudinesco, E., \& Plon, M. (1998). Dicionário de psicanálise. V. Ribeiro \& L. Magalhães (Trads.), M. A. C. Jorge (Ed.). Rio de Janeiro: Zahar.

Saffioti, H. (2004). Gênero, patriarcado e violência. São Paulo: Editora Fundação Perseu Abramo.

Salih, S. (2015). Judith Butler e a teoria queer. Belo Horizonte: Autêntica.

Stoller, R. J. (1982). A experiência transexual. Rio de Janeiro: Imago. 